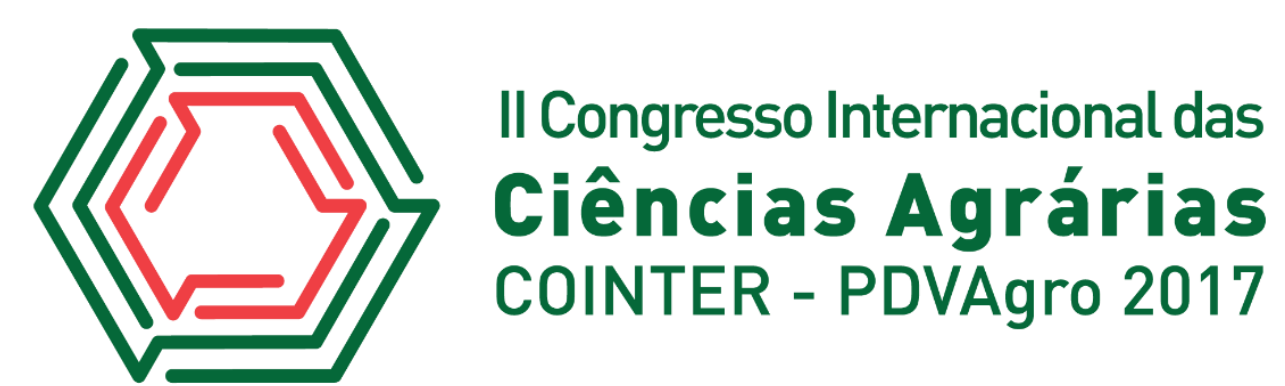

\title{
AVALIAÇÃO DA QUALIDADE DO ÓLEO E SUA CONVERSÃO EM BIODIESEL PARA DIFERENTES OLEAGINOSAS E MANEJOS FERTILIZANTES
}

\author{
Apresentação: Pôster
}

Jeane Medeiros Martins de Araújoㅜ; Bruno Alexandre Barreto²; Cristiano Cabral Santos ${ }^{3}$; Danubio Leonardo Bernardino de Oliveira ${ }^{4}$; Maria Dolores Raigón Jimenez ${ }^{5}$

\section{Introdução}

A busca por energias renováveis para diminuir a dependência do petróleo no presente e para o futuro é um objetivo estratégico. A obtenção de matérias-primas mais econômicas e sua composição é essencial para melhorar a rentabilidade do processo Entre as fontes de combustíveis, para a indústria e o fornecimento de energia para mover as principais vias de transporte (portos, aeroportos e carreteiras), o petróleo e seus derivados são a principal matéria prima. A problematização da característica não renovável do petróleo, portanto, sua finitude, além de alguns problemas técnicos, como a sua exploração difícil ou de alto impacto ambiental na cadeia de produção, fazem com que novas formas e alternativas energéticas sejam reivindicadas. A agroenergia, com o manejo de culturas alternativas e práticas de fertilização de baixo impacto, vem contribuir podendo dar origem ao biodiesel nas melhores condições de rentabilidade, com produção de diferentes aspectos agronômicos que influenciam a cultura, seu rendimento em óleo, e a qualidade dos azeites obtidos através do perfil de ácidos graxos. O principal objetivo deste trabalho é avaliar a qualidade do óleo de mamona (Ricinus communis L.), girassol (Helianthus annuus L.) e algodão (Gossypium hirsutum L.), dependendo do perfil lipídico e o potencial dos mesmos na reação de transesterificação para biodiesel, quando as culturas são cultivadas sob adubação orgânica ou técnicas convencionais.

\section{Fundamentação Teórica}

O descobrimento do petróleo e todo seu potencial energético desencadearam, no inicio do

\footnotetext{
${ }^{1}$ Tecnologia em Agroecologia, IFPB, jeane.araujo@ifpb.edu.br

2 Tecnologia em Agroecologia, IFPB, brunoalexandre64@hotmail.com

${ }^{3}$ Pós graduação em gestão dos recursos ambientais do semiárido, IFPB, cristiano.santos@ifpb.edu.br

${ }^{4}$ Pós graduação em gestão dos recursos ambientais do semiárido, IFPB, danubio.oliveira@ifpb.edu.br

${ }^{5}$ Doutora, Universidad Politécnica de Valencia, mdraigon@qim.upv.es
} 
século XX, uma nova revolução industrial representada, principalmente, pelo nascimento dos veículos movidos a compressão de motores de combustão interna, desenvolvidos por Rudolf Diesel ( Kucec, 2004), nos últimos anos, a maior parte da demanda energética global tem sido atendida por petróleo ou combustíveis fósseis, sendo o diesel uma de suas principais frações. Por outro lado, o petróleo é uma fonte de crise global, dando origem a modificações de preços, afetando a balança comercial de muitos países e de vários setores da economia e, consequentemente, o consumidor final ( Rochester, 2007). Além dessas mudanças que preocupam cada vez mais o setor de mercado de petróleo, o uso de combustíveis fósseis em grande escala no setor dos transportes, é um dos principais agentes de poluição do ar, causando danos através dos gases emitidos pelos motores, que afetam a qualidade do ar, causam chuva ácida e alteram os ecossistemas (SHER, 1998).

\section{Metodologia}

As sementes utilizadas na obtenção de óleo vieram de culturas de mamona, girassol e algodão sob diferentes manejos fertilizantes (uso de fertilizantes de síntese química, AQ, adubação orgânica, AE, e sem adubação SA), que foram realizadas durante safras de 2009 e 2010 na base experimental da Empresa de Pesquisa Agropecuária do Rio Grande do Norte (EMPARN) na região de Mato Grande no distrito de Pedro Avelino (Brasil).

Para a transesterificação de óleos de algodão e girassol foi usado uma reação catalisada em meio básico. Neste caso, utilizou-se $3 \mathrm{~g}$ de óleo misturado com $0,9 \mathrm{~g}$ de $\mathrm{KOH}$ em metanol, agitandose os reagentes de forma suave para evitar a formação de emulsão. Em seguida, deixou-se repousar durante $24 \mathrm{~h}$, em uma ampola de decantação para facilitar a separação. O biodiesel resultante foi transferido para um cilindro graduado de $10 \mathrm{ml}$ para medir o volume de biodiesel obtido. No caso da mamona, foi realizada uma microdestilação de refluxo em meio básico e por extração com hexano de biodiesel. Os resultados de desempenho em biodiesel são expressos em percentagem (m/v).

A determinação da composição de ácido graxo de óleo de rícino, de girassol e algodão, foi realizada por cromatografia gasosa utilizando uma coluna capilar, a partir dos ésteres metílicos obtidos por transesterificação, óleo frio, com uma solução metanólica de hidróxido de potássio.

\section{Resultados e Discussões}

Os ácidos graxos quantificados nos azeites foram mirístico, palmítico, palmitoleico, heptadecanóico, heptadecenoico, esteárico, oleico, linoleico, araquidonico, linolênico, eicosanóico, behénico, lignocérico e erúcico. De todos os ácidos graxos, os que estão presentes na maioria são os 
ácidos oleico, linoleico, palmítico e esteárico, os dois últimos variam dependendo do tipo de óleo. E aqueles que estão em menor concentração são mirístico, palmitoléico, eicosanóico, araquidônico e heptadecanóico. O resto das concentrações são extremamente baixas, $\pm 0,01 \%$ ou não significativas.

A Tabela 1 mostra os valores médios obtidos de conteúdo individual nos principais ácidos graxos nos três óleos (mamona, girassol e algodão), para os três tratamentos de fertilizantes nas duas campanhas de estudos. O perfil lipídico pode ser interpretado como os óleos de identificação de impressões digitais, tais como a maioria de óleo de mamona que corresponde a um valor de ácido oleico de aproximadamente 30-33\%, linoleico 37-41\%, 3,5-4\% linolênico, 8-9\% palmítico, esteárico 7,4-8,8\%. O óleo de girassol tem aproximadamente entre 51 e 54\% de ácido oleico, 35 a $38 \%$ linoleico, linolênico valores muito baixos (cerca de 0,04\%), entre 5 e $9 \%$ e cerca palmítico 3\% esteárico. No óleo de semente de algodão entre 17-18\% é o ácido graxo oleico, de 52 a $54 \%$ linoleico, de 0,12\% para 0,15 linolênico, de 23 a 24\% palmítico e 2,4\% esteárico.

Karleskind, (1996) uma percentagem aproximada é relatada na composição de ácidos graxos de óleo de mamona de $1 \%$ de ácido palmítico, $1 \%$ de ácido esteárico, 3\% de ácido oleico, 3-4\% de ácido linoleico e 89-90\% de um ácido ricinoleico $(\mathrm{C} 18: 1(\mathrm{OH}))$. Esta composição difere significativamente da obtida no presente trabalho, devido às condições do programa cromatográfico utilizado. Além disso, estudos de Lang et al. (2001) indicam que a maioria da fração lipídica do óleo de mamona é de 67,2\% de ácido oleico, 18,9\%, ácido linoleico, 7,4\% de ácido linolênico, 4,2\% de ácido palmítico e 2,2\% de ácido esteárico. Tendo em conta a variabilidade dos resultados, a fração de ácidos graxos obtidos no presente estudo é considerada válido, em comparação com outros óleos estudados.

Para a composição lipídica do óleo de semente de algodão, Segundo Demirbás, (2003) ressalta a oscilação em torno de $13 \%$ do ácido oleico no óleo de algodão. Para o presente trabalho essa oscilação varia entre 17 e 18\%, uns 28 a 29\% para o ácido palmítico, e cerca de $1 \%$ de esteárico, para o teor de ácido graxo linoleico, entre 57 e 57,4\%, sendo os demais de concentrações insignificantes.

Tabela 1. Composição (\%) da maioria dos ácidos graxos nos óleos de mamona, girassol e algodão, nos três tratamentos de fertilizantes nas duas campanhas.

\begin{tabular}{llllllll}
\hline Campanha & Cultivo & Tratamento & $\begin{array}{l}\text { Oleico } \\
(\mathrm{C} 18: 1)\end{array}$ & $\begin{array}{l}\text { Linoleico } \\
(\mathrm{C} 18: 2)\end{array}$ & $\begin{array}{l}\text { Linolênico } \\
(\mathrm{C} 18: 3)\end{array}$ & $\begin{array}{l}\text { Palmítico } \\
(\mathrm{C} 16: 0)\end{array}$ & $\begin{array}{l}\text { Esteáricoo } \\
(\mathrm{C} 18.0)\end{array}$ \\
\hline \multirow{4}{*}{2009} & AE & $31,10 \%$ & $37,89 \%$ & $3,42 \%$ & $8,77 \%$ & $8,45 \%$ \\
& \multirow{2}{*}{ Rícino } & AQ & $30,71 \%$ & $39,02 \%$ & $3,56 \%$ & $8,10 \%$ & $7,62 \%$ \\
& & SA & $30,83 \%$ & $38,80 \%$ & $3,07 \%$ & $7,81 \%$ & $7,44 \%$ \\
\cline { 3 - 7 } & \multirow{2}{*}{ Girassol } & AE & $51,96 \%$ & $38,46 \%$ & $0,031 \%$ & $4,97 \%$ & $2,83 \%$ \\
& AQ & $53,87 \%$ & $36,44 \%$ & $0,035 \%$ & $5,01 \%$ & $2,85 \%$ \\
\hline
\end{tabular}




\begin{tabular}{|c|c|c|c|c|c|c|c|}
\hline & & SA & $54,84 \%$ & $35,38 \%$ & $0,040 \%$ & $5,04 \%$ & $2,81 \%$ \\
\hline & \multirow{3}{*}{ Algodão } & $\mathrm{AE}$ & $18,13 \%$ & $51,85 \%$ & $0,12 \%$ & $24,78 \%$ & $2,48 \%$ \\
\hline & & $A Q$ & $17,24 \%$ & $54,12 \%$ & $0,12 \%$ & $23,49 \%$ & $2,47 \%$ \\
\hline & & SA & $17,65 \%$ & $52,23 \%$ & $0,12 \%$ & $24,93 \%$ & $2,38 \%$ \\
\hline \multirow{9}{*}{2010} & \multirow{3}{*}{ Rícino } & $A E$ & $33,32 \%$ & $40,65 \%$ & $4,19 \%$ & $8,78 \%$ & $8,56 \%$ \\
\hline & & $A Q$ & $33,54 \%$ & $40,72 \%$ & $3,84 \%$ & $8,53 \%$ & $8,35 \%$ \\
\hline & & SA & $32,37 \%$ & $41,13 \%$ & $3,44 \%$ & $9,28 \%$ & $8,78 \%$ \\
\hline & \multirow{3}{*}{ Girassol } & $\mathrm{AE}$ & $53,93 \%$ & $36,00 \%$ & $0,034 \%$ & $5,15 \%$ & $3,08 \%$ \\
\hline & & $A Q$ & $53,58 \%$ & $35,76 \%$ & $0,06 \%$ & $5,50 \%$ & $3,28 \%$ \\
\hline & & SA & $54,16 \%$ & $35,94 \%$ & $0,05 \%$ & $5,30 \%$ & $2,81 \%$ \\
\hline & \multirow{3}{*}{ Algodão } & $\mathrm{AE}$ & $17,12 \%$ & $53,26 \%$ & $0,13 \%$ & $24,24 \%$ & $2,47 \%$ \\
\hline & & $A Q$ & $17,35 \%$ & $53,41 \%$ & $0,13 \%$ & $24,03 \%$ & $2,40 \%$ \\
\hline & & SA & $18,12 \%$ & $53,46 \%$ & $0,15 \%$ & $23,68 \%$ & $2,38 \%$ \\
\hline
\end{tabular}

A Figura 1 mostra os níveis médios de desempenho na obtenção de biodiesel. Embora as diferenças globais obtidas não sejam significativas, são notáveis os rendimentos individuais em cada caso. Sementes oriundas de cultivo ecológico (AE), geram óleos que favorecem a transesterificação do biodiesel, sendo mais evidente no algodão, com 94,33\% de óleo transesterificado. Os ácidos graxos encontrados no óleo de rícino, de girassol e algodão foram linoleico, oleico, palmítico e esteárico, em conjunto, representam mais de $90 \%$ do total. Destacando o linoleico entre os ácidos graxos secundários, com alguma relevância para o cultivo da mamona, independentemente do sistema de fertilização, e girassol, somente quando fertilizado em condições de agricultura ecológica. Os rendimentos na transesterificação de óleos de sementes de algodão de fertilização orgânica foram 2,48\% maior do que o obtido com a transesterificação de óleo de semente de algodão obtido a partir de sementes de plantas não fertilizadas, e 13,5\% mais elevado do que os obtidos com sementes de óleo de algodão a partir de plantas fertilizadas convencionalmente. No caso do óleo de girassol, o rendimento em biodiesel obtido a partir das sementes de plantas de fertilização orgânica foi 2,6\% superior que o rendimento de biodiesel em óleos a partir de sementes de girassol com tratamento sem fertilização, e 9,42\% acima do rendimento de biodiesel obtido a partir do óleo de sementes de plantas quimicamente fertilizadas. No caso do óleo de mamona, o rendimento mais elevado de biodiesel é obtido com o tratamento de fertilização química, obtendo-se $5 \%$ a mais do que no caso de óleos de fertilização orgânica, e 3,4\% mais do que o correspondente de óleos obtidos a partir de plantas não fertilizadas.

Figura 1. Os valores médios do rendimento (\%) de biodiesel de óleo, dependendo da cultura e de tratamento. 


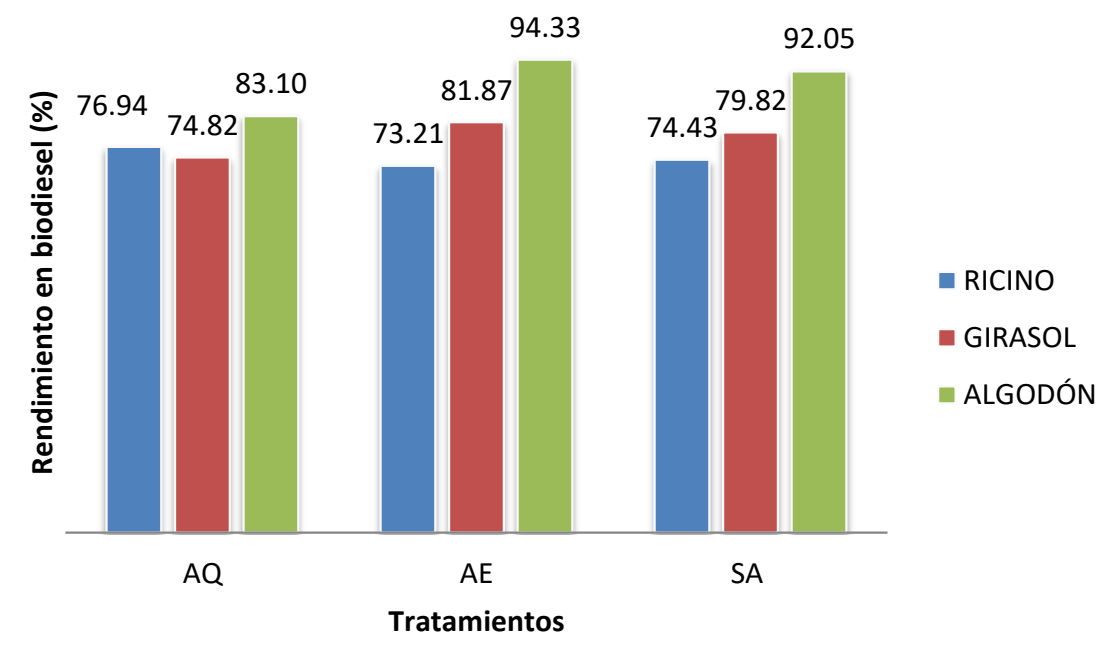

Para Moreira Santos (2012) recomenda-se a mistura do óleo para a melhor transesterificação e, portanto, no desempenho de biodiesel. Com base nos resultados, o melhor desempenho em biodiesel e, portanto, as melhores propriedades poderiam ser obtidos a partir do óleo de algodão, seguido do óleo de girassol, sendo o mix destes azeites uma possibilidade de produção de um biocombustível de qualidade e adequação à legislação vigente sobre biodiesel.

\section{Conclusões}

Podem ser obtidos elevados níveis de biodiesel a partir de óleos de sementes de algodão quando os conteúdos de óleo são elevados e têm baixos conteúdos de ácidos linoleico e oleico, eicosanoico, esteárico, mirístico e behénico.

\section{Referências}

Demirbas, A. 2003. Biodiesel fuels from vegetable oils via catalytic and non-catalytic supercritical alcohol transesterifications and other methods: a survey. Energy Convers Manage, 44: 2093-109

Karleskind, A. 1996. Oils and fats manual: a comprehensive treatise: properties, production, applications. Ed. Lavoisier Publishing. Paris. Volumes 1 \& 2: 807-1572.

Kucek, K. T. Otimização de transesterificação etílica do óleo de soja em meio alcalino. Dissertação (123 f) Mestrado em Química Orgânica, Universidade Federal do Paraná - UFPR. Curitiba-PR. 2004.

Moreira Santos, E. 2012. Principales características de las materias primas utilizadas en la producción de biodiesel: la influencia del contenido y la concentración de los ácidos grasos. Ingenium, 13(25): 53-61.

Rochester, I. J. Nutrient uptake and export from an Australia cotton field. Nutrient Cycling in Agroecosystems, Dordrecht, v 77, p. 213-223, 2007.

Sher, E. 1998. Handbook of air pollution from internal combustion engines. Pollutant formation and control. Academic Press. San Diego. 665 pp. 